www.nature.com/ejhg

\title{
Replication and extension studies of inflammatory bowel disease susceptibility regions confirm linkage to chromosome 6p (IBD3)
}

\author{
Bryan Dechairo*,1,2, Claire Dimon ${ }^{1}$, David van Heel ${ }^{3,4}$, Ian Mackay ${ }^{1}$, Mark Edwards ${ }^{1}$, \\ Peter Scambler ${ }^{2}$, Derek Jewell ${ }^{3}$, Lon Cardon ${ }^{4}$, Nicholas Lench ${ }^{1}$ and Alisoun Carey ${ }^{1}$ \\ ${ }^{1}$ Oxagen Ltd., Abingdon, Oxfordshire, UK; ${ }^{2}$ Molecular Medicine Unit, Institute of Child Health, University College \\ of London, London, UK; ${ }^{3}$ Gastroenterology Unit, Nuffield Department of Medicine, Radcliffe Infirmary, Oxford, \\ UK; ${ }^{4}$ Wellcome Trust Centre for Human Genetics, University of Oxford, UK
}

Inflammatory bowel disease (IBD) is a chronic inflammatory disease of the intestine, commonly diagnosed as either ulcerative colitis (UC) or Crohn's disease (CD). Epidemiological studies have consistently shown that both genetic and environmental factors influence the pathogenesis of IBD. A number of genome scans have been conducted in cohorts of IBD families with affected sibling pairs (ASPs) to identify chromosomal regions that harbour IBD susceptibility genes. Several putative linked loci have been identified, including two loci on chromosomes 16 and 12, IBD1 and IBD2, which have subsequently been replicated by independent regionspecific studies. We have conducted both a replication study on another linkage region, chromosome $6 \mathrm{p}$ (IBD3), and extension studies on two other regions, chromosomes $3 p$ and $7 q$. Microsatellite markers across each region were genotyped in 284 IBD ASPs from 234 families. A nonparametric peak multipoint LOD score of 3.0 was observed near D6S291, replicating the previous linkage to chromosome 6p (IBD3). Nominal evidence of linkage was observed at both the $3 p$ and $7 q$ regions. European Journal of Human Genetics (2001) 9, $627-633$.

Keywords: inflammatory bowel disease; Crohn's disease; ulcerative colitis; linkage; sib-pair; replication

\section{Introduction}

Crohn's disease (CD) and ulcerative colitis (UC), the two most common forms of inflammatory bowel disease (IBD), are idiopathic inflammatory diseases of the intestine. CD can affect any part of the gastrointestinal tract and is typically characterised by a segmental distribution of transmural inflammation, deep ulceration, strictures, and fistulae. In contrast, UC normally onsets in the rectum (proctitis) and is limited to the colon, exhibiting a continuous pattern of inflammation and ulceration of only the colonic mucosa. ${ }^{1,2}$

Considering UC and CD together, IBD is a common disease with a prevalence in European and North American

*Correspondence: Bryan Michael Dechairo, Oxagen Ltd., 91 Milton Park, Abingdon, Oxfordshire, OX14 4RY, UK. Tel: +44 1235 443319;

Fax: +44 1235 443301; E-mail: b.dechairo@oxagen.co.uk

Received 15 January 2001; revised 9 May 2001; accepted 16 May 2001
Caucasians of $126-215$ per $100000 .^{3-6}$ Aetiology is unknown but is predicted to involve complex interactions between genetic susceptibility and environmental factors. Studies have shown a first-degree relative risk for IBD of 6-15 and six times higher rates of concordance between monozygotic twins $v$ s dizygotic twins. ${ }^{3,5,7-9}$ In most families the increase in risk is for the same type of IBD but studies have shown that there is also an increase for the discordant phenotype. This overlap between $\mathrm{CD}$ and UC has been observed at diagnosis, where up to $10 \%$ of cases are labelled as indeterminate colitis. In these cases, review of clinical, endoscopic, and histological data is unable to establish with certainty the disease type. ${ }^{6}$ Overall, genetic epidemiological studies suggest that each disease results from its own susceptibility loci, other loci that are shared, and environmental influences.

To date, seven genome scans in search of IBD susceptibility loci have been published. Each study contained a different number of families and affected 
Table 1 Summary of IBD cohort used for linkage analysis

sib-pairs (ASPs) and consequently each had a different power to detect linkage. The largest genome scan for IBD susceptibility loci contained 353 ASPs; ${ }^{10}$ other studies contained 183 ASPs, ${ }^{11} 151$ ASPs, ${ }^{12} 94$ ASPs, ${ }^{13} 89$ ASPs, ${ }^{14}$ 65 ASPs, ${ }^{15}$ and 41 ASPs. ${ }^{16}$ The proportion of CD, UC, and mixed cases in each of these studies differed. Using the criteria of Lander and Kruglyak, ${ }^{17}$ these studies resulted in significant linkage for IBD to chromosomes 6p (IBD3 [MIM 604519]), ${ }^{18} 19 \mathrm{p}^{11}$ and $12 \mathrm{q}$ (IBD2 [MIM 601458]), ${ }^{14}$ and significant linkage for $C D$ to chromosomes 5q31$33,{ }^{11} 14 \mathrm{q} 11-12,{ }^{13}$ and the pericentromeric region of chromosome 16 (IBD1 [MIM 266600]). ${ }^{16}$ Only the IBD1 and IBD2 loci have been replicated by independent multipoint studies in addition to other genome scans. ${ }^{14,15,19-24}$

Given that (1) the power to detect linkage increases with the size of the family cohort, and (2) our expanded cohort of 284 IBD affected sib pairs includes families analysed by Satsangi et al, ${ }^{14}$ which resulted in suggestive linkage to both $3 p$ and $7 q$, we genotyped a dense set of microsatellite markers spanning these two suggestive linkage regions in order to increase information content and potentially extend the significance of linkage. In addition, since the IBD3 locus has not been confirmed by independent region-specific replication, we conducted a replication study across the $6 \mathrm{p}$ region using markers from the original study. ${ }^{18}$

\section{Subjects and methods \\ Families}

Ethical approval was obtained from the Central Oxford Research and Ethics Committee (COREC) for the collection of IBD families and their subsequent participation in genetic studies. A total of 234 UK Caucasian families, none of which were Jewish, were identified for the present study. Of the 234 families, 151 were included in a previous two-stage genome scan (SIBS1\&2). ${ }^{14}$ The families consisted of 107 CD, 78 UC, and 49 mixed families. Mixed families were defined as those containing any first- or second-degree relative with a discordant form of IBD. Two of the families comprised two generations of affected siblings, giving a total of 236 nuclear families. Of the nuclear families, 212 contained two affected siblings and 24 contained three affected siblings. In total, there were 284 IBD ASPs, consisting of 143 CD, 90 UC and 51 mixed ASPs (Table 1). Parents were collected whenever possible, resulting in 101 nuclear families with both parents, 64 with only one parent and 71 with neither parent. Of those families containing no parents, 27 included at least one unaffected sibling. Diagnosis of IBD and sub-classification as CD or UC were determined by the use of standard diagnostic criteria. ${ }^{25}$ Venous blood samples were taken from all subjects and DNA was prepared from whole blood using either the Puregene kit (Gentra Systems) or phenol/chloroform extraction.

\begin{tabular}{lcllc}
\hline $\begin{array}{l}\text { Family type/ } \\
\text { affected sibs }\end{array}$ & CD (ASPs) & UC (ASPs) & Mixed (ASPS) & IBD (ASPs) \\
\hline $\mathrm{CD} / 2$ & $94(94)$ & - & - & $94(94)$ \\
$\mathrm{CD} / 3$ & $13(39)$ & - & - & $13(39)$ \\
UC/2 & - & $72(72)$ & - & $72(72)$ \\
UC/3 & - & $5(15)$ & - & $5(15)$ \\
UC/2G-2 & - & $1(2)$ & - & $1(2)$ \\
Mixed/2 & $2(2)$ & - & $40(40)$ & $42(42)$ \\
Mixed/3 & $5(7)$ & $1(1)$ & $5(10)$ & $6(18)$ \\
Mixed/2G-2 & $1(1)$ & - & $1(1)$ & $1(2)$ \\
Total & $115(143)$ & $79(90)$ & $46(51)$ & $234(284)$ \\
\hline
\end{tabular}

Note-'2G-2' denotes an extended family with two generations of ASPs. Mixed family type refers to any family with at least one firstor second-degree relative with a discordant form of IBD. Mixed ASPs denotes any sibling pair with discordant forms of IBD.

\section{Genotyping}

A total of 41, 29 and 10 highly polymorphic, fluorescentlabeled microsatellite markers spanning the putative linkage regions on chromosome $3 p, 7 q$ and $6 p$ respectively, were genotyped across the IBD family DNA (Table 2). Using the RAPIDGene ${ }^{(m)}$ automated genotyping system (Oxagen Ltd.), each marker was amplified by PCR across ten 96-well plates of DNA and pooled into sets. The pooled DNA was then denatured, loaded onto a polyacrylamide gel, and electrophoresed on an ABI 377 machine. Analysis of the genotypes was conducted using ABI GENESCAN (version 3.0) and stored in Discovery Manager ${ }^{(i)}$ (Genomica Corporation) together with the pedigree and phenotype data for each individual.

To resolve marker-marker order and generate a map inclusive of all genotyped markers, radiation hybrid (RH) mapping using the Stanford G3 Panel (Research Genetics) was carried out (Table 2). For the $3 p$ and $7 q$ saturation regions, marker order and distance was calculated from the $\mathrm{RH}$ results using RHMAP (version 2.01). ${ }^{26}$ However, due to the increased distance between markers analysed in the chromosome 6 region, the $6 \mathrm{p}$ map was constructed by sending the RH data to the Stanford RH Server. ${ }^{27}$ Resulting physical distances were converted to genetic distances under the assumptions of $1 \mathrm{cR}_{10,000}=25 \mathrm{~kb}$ and $1000 \mathrm{~kb}=1 \mathrm{cM}$.

Quality control of genotypes was performed using Pedcheck (version 1.1) ${ }^{28}$ to check for Mendel errors and CRI-MAP ${ }^{29}$ to check for double recombinants. Genetic maps were built using MultiMap (version 2.0) ${ }^{30}$ and compared to the RH maps to confirm genotypes and marker order.

\section{Statistical genetics}

Nonparametric multipoint linkage analyses across the 3p, $6 \mathrm{p}$, and $7 \mathrm{q}$ linkage regions were performed using MAPMAKER/ SIBS implemented within GENEHUNTER (version 2.0). ${ }^{31}$ All affected sib pairs in each pedigree were counted, using the 'weighted' option. GENOTYPER (version 2.0) software. Genotype data was 
Table 2 Genotyped markers and corresponding inter-marker distance and order

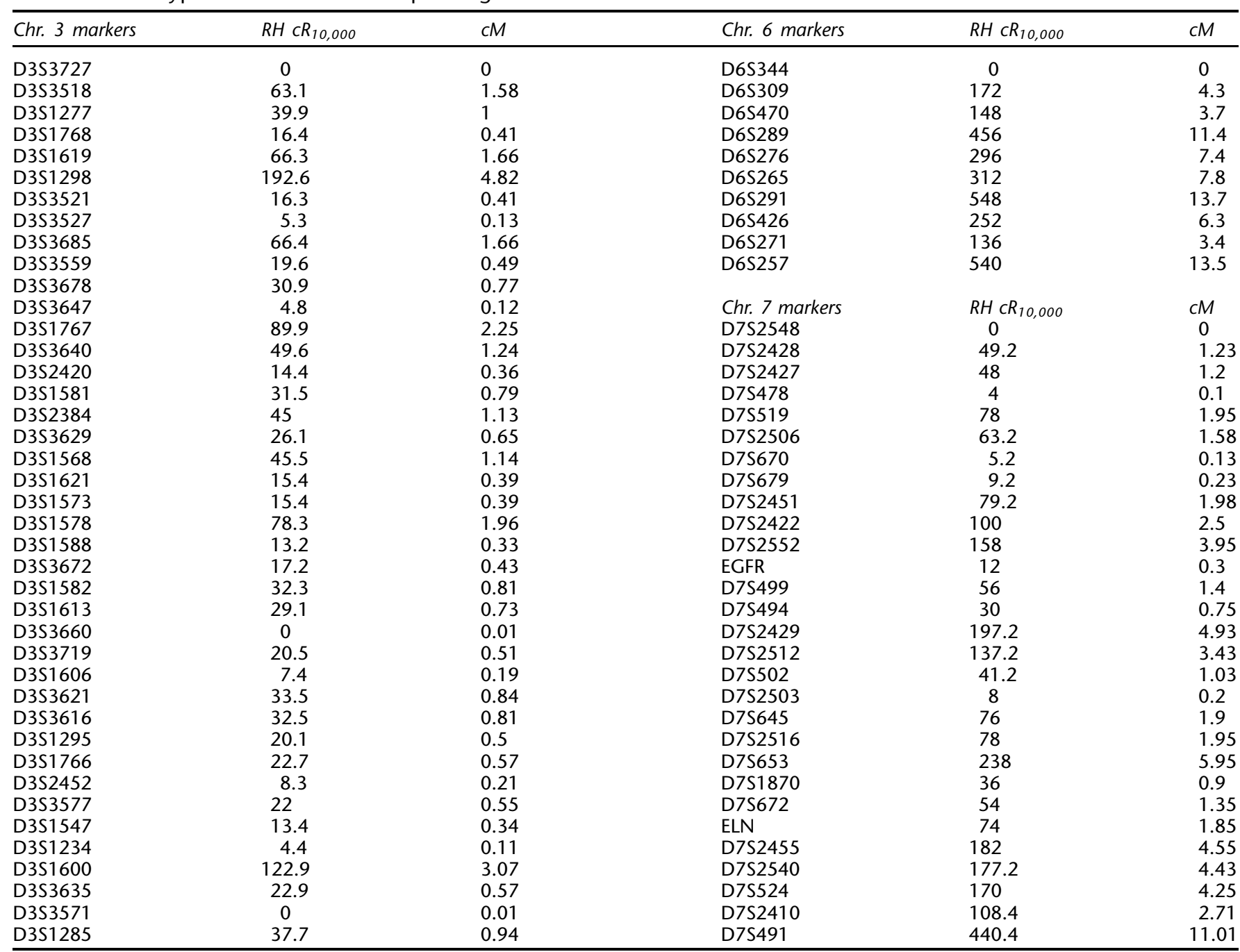

Note-Markers appear in order from $\mathrm{p}$ to $\mathrm{q}$ arm. $1 \mathrm{CR}_{10,000}$ is approximately equivalent to $25 \mathrm{kB}$. The genetic distances were derived under the assumption of $1000 \mathrm{~kb}=1 \mathrm{cM}$.

Analysis was performed under conditions that included the possibility of dominance variance. All data were analysed under three phenotype models: (1) any form of IBD designated as affected; (2) only CD patients designated as affected; and (3) only UC patients designated as affected. Allele frequencies for each microsatellite marker were calculated using available genotypes from all individuals in every pedigree, both affected and unaffected. The allele frequencies were consistent with those generated by genotyping the same markers in other independent populations. The RH map generated for each region was utilised within MAPMAKER/SIBS for marker order and spacing. The information content from each marker was calculated by the GENEHUNTER program within the linkage analysis package.

TDT association analysis was performed within GENEHUNTER (version 2.0) using the TDT function. Subsequently, to test how frequently the results could be achieved by chance, 1000 randomly generated equivalent data sets were analysed using the Perm1 function.

\section{Results \\ Genotyping}

More than 70000 genotypes were generated from the extension studies on $3 p$ and $7 q$ and the replication study on $6 \mathrm{p}$. The data set was $99.5 \%$ complete, with $0.2 \%$ genotypes missing due to PCR failure, $0.1 \%$ removed due to unresolved PedCheck errors, $0.1 \%$ removed due to CRI-MAP identification of double recombinants, and $0.1 \%$ removed due to microsatellite mutation. In overall length and marker order, the map output from MultiMap was comparable to the RH map generated for each region. However, only 14/41 and 
$19 / 29$ markers were ordered (LOD $>3.0$ ) in the $3 p$ and $7 q$ genetic maps respectively, due to the lack of informative recombinants resulting from the proximity of the markers and the number of families (Figure 1). After conversion of the

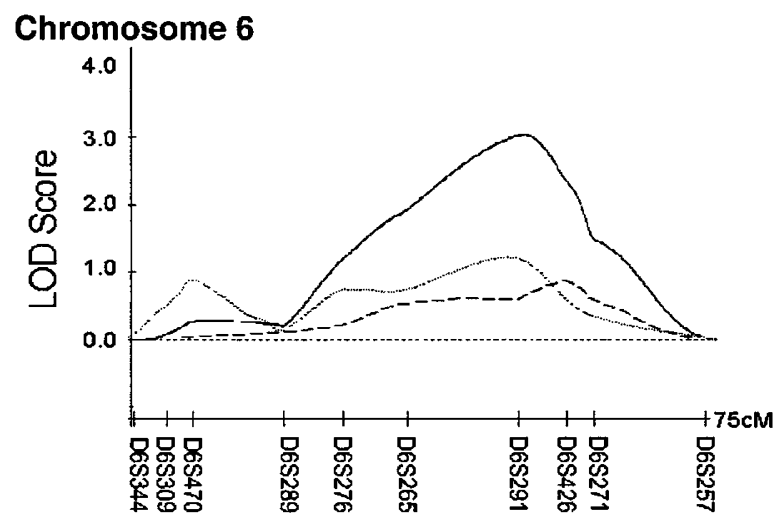

Chromosome 3
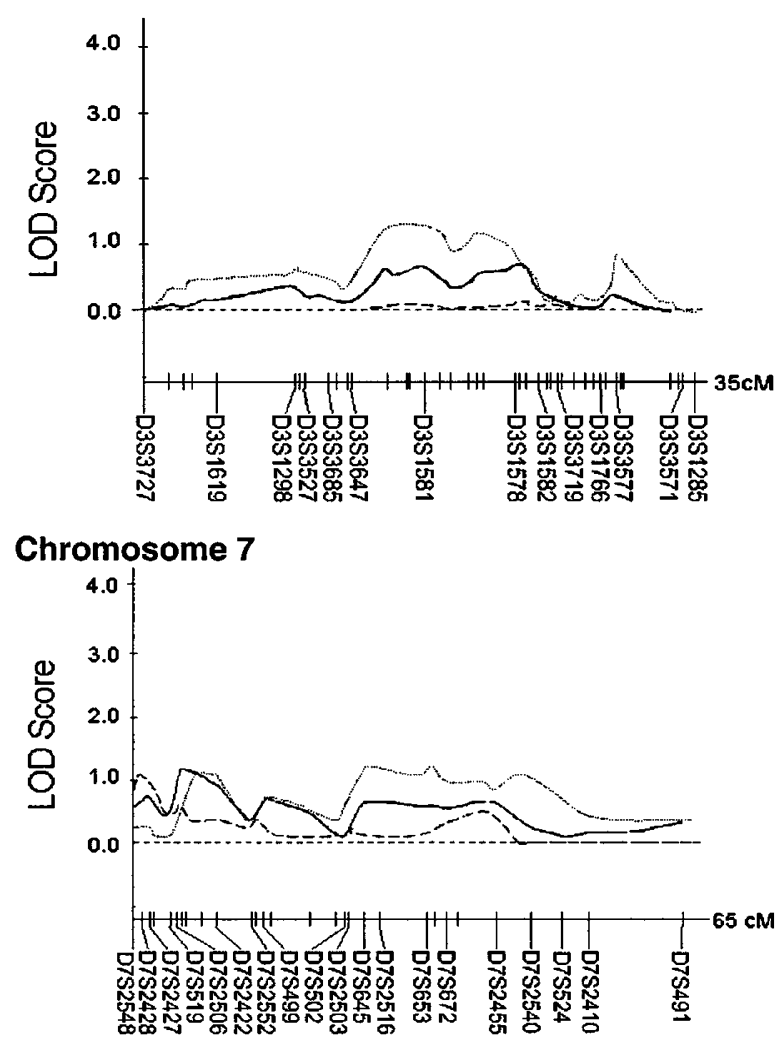

Figure 1 Nonparametric multipoint MLS curves for the chromosome 6, 3 and 7 IBD linkage regions. Results for the IBD (bold solid line), CD (thin solid line), and UC (dashed line) phenotype models are shown. Marker-marker order and distance was calculated from $\mathrm{RH}$ mapping results (Table 2). The markers shown for the chromosomes 3 and 7 regions correspond to the markers resulting from the MultiMap output for each interval.
RH maps from cR to cM, the 41 markers on 3p, 29 markers on $7 \mathrm{q}$ and 10 markers on $6 \mathrm{p}$ spanned a region of approximately 35,65 , and $75 \mathrm{cM}$ respectively (Table 2 ).

\section{Statistical genetics}

The average information content across the $3 \mathrm{p}, 7 \mathrm{q}$, and $6 \mathrm{p}$ region was $0.91,0.86$ and 0.76 respectively. The peak multipoint LOD score for each region under each phenotype model is given in Table 3 .

Positive linkage was detected in the $6 \mathrm{p}$ region with a nonparametric peak multipoint LOD score of 3.04 near D6S291 for IBD (Figure 1). The mean allele sharing (MAS) at the point of peak linkage was 0.58 (Table 3 ). There was almost equal contribution from CD and UC ASPs to the linkage, as shown by the similar $\lambda_{\mathrm{s}}$ values $\left(0.25 / \mathrm{z}_{\mathrm{o}}\right)$ of $1.2,1.2$, and 1.3 , calculated for each of the phenotype models, IBD, CD, and UC respectively. The ability to detect linkage to a locus with a $\lambda_{\mathrm{s}}$ of only 1.2 is directly related to the power of the study, and thus when the IBD cohort was divided into sub-populations of UC and CD positive linkage was not observed.

With positive linkage to the $6 \mathrm{p}$ region, TDT analysis using the linkage genotype data was performed across the region with all IBD phenotype models. Positive association was detected between UC and an allele from D6S271 ( $P=0.007)$. However, 1000 simulations with random data sets of equivalent size resulted in 187 data sets of greater significance. Association was not detected with either IBD or CD.

Linkage was not detected in either the $3 p$ or the $7 \mathrm{q}$ region. The largest LOD score for each region was 1.25 for $\mathrm{CD}$ at D3S3640-D3S1581 and 1.26 for CD at D7S645-D7S2516 (Figure 1). Similar results were seen in the re-analysis of SIBS1\&2, using the newly generated genotypes (Table 3).

\section{Discussion}

IBD genome scans have resulted in several regions of linkage. However, only two regions have been subsequently replicated by independent region-specific studies. Recently, Hampe $e a^{18}$ reported linkage to $6 \mathrm{p}$ in an extension study using the largest IBD population to date (428 ASPs). In the present study, we have replicated the $6 \mathrm{p}$ linkage in our IBD population containing 284 ASPs. The nonparametric peak multipoint LOD score of 3.04 near D6S291 exceeds the proposed criteria for independent replication of significant linkage $(\mathrm{LOD}=1.5) .{ }^{17}$ However, while this represents the first region-specific replication study of the IBD3 locus, both a recent genome scan by Rioux et $a^{11}$ and an earlier candidate gene study by Yang et $a l^{32}$ also reported suggestive linkage to $6 \mathrm{p}$ between D6S1281 and D6S1019 in a cohort of 183 IBD ASPs (LOD=2.3) and around TNF in a cohort of 70 CD ASPs $(P=0.002)$, respectively. All three IBD studies showed linkage contributed by both the UC and the CD populations. However, both the linkage peak from the Rioux et al ${ }^{11}$ study and the peak from our study were approximately $15 \mathrm{cM}$ proximal to the initial reports of linkage. ${ }^{18,32}$ This discre- 
Table 3 Peak multipoint nonparametric linkage results

\begin{tabular}{|c|c|c|c|c|c|c|}
\hline $\begin{array}{l}\text { Chromosomal region/ } \\
\text { phenotype model }\end{array}$ & $\begin{array}{l}\text { Marker(s) } \\
\text { extended cohort }\end{array}$ & $\begin{array}{l}\text { LOD score } \\
\text { extended cohort }\end{array}$ & $\begin{array}{l}\text { MAS } \\
\text { extended cohort }\end{array}$ & $\begin{array}{l}\text { Marker(s) } \\
\text { SIBS1\&2 }\end{array}$ & $\begin{array}{l}\text { LOD score } \\
\text { SIBS1\&2 }\end{array}$ & $\begin{array}{l}\text { MAS } \\
\text { SIBS1\&2 }\end{array}$ \\
\hline $6 \mathrm{p} / \mathrm{IBD}$ & D6S291 & 3.04 & 0.58 & - & - & - \\
\hline $6 \mathrm{p} / C D$ & D6S291 & 1.23 & 0.57 & _ & _ & _- \\
\hline $3 \mathrm{p} / \mathrm{IBD}$ & D3S1588-D3S3672 & 0.68 & 0.54 & D3S3672-D3S1582 & 1.19 & 0.55 \\
\hline $3 p / C D$ & D3S3640-D3S1581 & 1.25 & 0.58 & D3S1581-D3S2384 & 1.21 & 0.59 \\
\hline $3 p / U C$ & D3S1588-D3S3672 & 0.09 & 0.53 & D3S3672-D3S1582 & 0.74 & 0.57 \\
\hline
\end{tabular}

pancy is not surprising since differences between actual gene location and peak linkage are not unexpected in complex traits. ${ }^{33}$ Taken together the results support the existence of an IBD susceptibility locus at $6 \mathrm{p}$ (IBD3).

Confirmation of the linkage to $6 \mathrm{p}$ now warrants highdensity association studies across the region, potentially starting with good positional candidate genes. The IBD3 locus contains the MHC region, which has been implicated in other linkage studies of autoimmune diseases including inflammatory diseases such as asthma, arthritis and psoriasis. ${ }^{34}$ This overlap of susceptibility regions suggests that a $\mathrm{MHC}$ autoimmune susceptibility gene may be responsible for the positive linkage results. In previous studies, DRB1, TNF $\alpha$, and other MHC genes have already shown positive association to IBD. ${ }^{35-50}$ However, another hypothesis is that the overlap of disease susceptibility loci could indicate an inflammation specific disease gene in the region. One potential inflammation candidate gene is cytokine suppressive anti-inflammatory binding protein 1 (CSBP1). CSBP1 RH maps directly adjacent to D6S291, the peak linkage marker in this study. Still, even with multiple overlapping disease linkage regions, the potential of finding an IBD specific disease gene in the region should not be ignored. Recently, peroxisome proliferator activated receptor gamma $(\operatorname{PPAR} \gamma)$ was implicated in IBD, ${ }^{51}$ which suggests that a family member like $\operatorname{PPAR} \delta$, which again maps adjacent to D6S291, could also be implicated. Not until all IBD, inflammation and autoimmune candidate genes within the region have been thoroughly tested for association to IBD may it be possible to understand all susceptibility conferred by the IBD3 locus.

To better stratify the numerous IBD linkage regions by their effect on the disease population, it is important that extension studies are conducted on genome scan linkage regions when the size of the ASP cohort increases. With the exception of the significant IBD linkage regions on $14 \mathrm{q}$ and $19 \mathrm{p}$, all other significant (LOD>3.59) IBD linkages have resulted from studies across suggestive loci in expanded cohorts. ${ }^{11,13,14,16,18}$ In the present study, we revisited the suggestive loci resulting from the Satsangi et al ${ }^{14}$ genome scan on $3 p$ and $7 q$ by conducting extension studies in each region with an expanded population of 284 IBD ASPs.
Linkage was not detected in either region for any phenotype model. Due to the difference in results from this extension study and the previous genome scan by Satsangi et al, ${ }^{14}$ the 151 families included in the previous study were analysed again separately. Since, the additional families used in the present study were ascertained using the same criteria as used previously (re: clinical profile, ethnicity, family size), the differences in results may either be caused by genetic heterogeneity or by difference in the methodology of analysis. The analysis showed that the present SIBS $1 \& 2$ data for $3 p$ and $7 q$, with respective MAS of 0.55 and 0.55 , was consistent with the extension results rather than the previously published genome scan results (MAS of 0.63 and 0.64 , respectively). Thus, the differences between the two studies are more likely to be caused by lower information content, due to the previous use of two-point analysis rather than multipoint analysis.

Since the publication of the genome scan by Satsangi et $a l^{14}$ other independent region-specific studies in these regions have been conducted. ${ }^{23,24,52,53}$ These studies also failed to see linkage. To date, six genome scans and four replication studies have failed to detect linkage to chromosome 7. It has been noted that suggestive linkage will occur by chance once per genome scan ${ }^{17}$ and thus the linkage to $7 \mathrm{q}$ detected in our previous genome scan may be a false positive. Conversely, a recent genome scan by Rioux et al ${ }^{11}$ has reported linkage to the chromosome 3 region, with a LOD of 2.4 , and thus the $3 p$ interval may contain a gene of small effect on IBD aetiology.

In summary, we have replicated linkage to the $6 \mathrm{p}$ region and have failed to extend linkage to the $3 p$ and $7 q$ regions. These replication and extension studies, together with others like them, will help in the stratification of linkage regions by their relative impact on IBD susceptibility.

\section{Acknowledgments}

The authors would like to thank the physicians, patients and their families, and the National Association for Colitis and Crohn's Disease, UK. We acknowledge Dr Keri Aitchison, Daphne Lever, Heather Holt and the research nurses for assistance in patient 
collection and John Herbert, Gordon Duncan and the Oxagen Limited support team for their technical assistance. D van Heel is a Medical Research Council Clinical Training Fellow. A MRC LINK Grant has supported this research.

\section{References}

1 Sorensen HT, Fonager KM: Myocarditis and inflammatory bowel disease. A 16-year Danish nationwide cohort study. Dan Med Bull 1997; 44: $442-444$.

2 McConnell RB, Vadheim CM: Inflammatory Bowel Disease; in King RA, Rotter JI, Motulsky AO (eds): The Genetics Basis of Common Diseases. Oxford, 1992, pp 326-348.

3 Cipolla C, Magliocco A, Oliva L, Cottone M: Familial aggregation of inflammatory bowel disease in a Mediterranean area. Eur J Epidemiol 1996; 12: 205 - 210.

4 Probert CS, Jayanthi V, Hughes AO, Thompson JR, Wicks AC, Mayberry JF: Prevalence and family risk of ulcerative colitis and Crohn's disease: an epidemiological study among Europeans and south Asians in Leicestershire. Gut 1993; 34: 1547-1551.

5 Orholm M, Munkholm P, Langholz E, Nielsen OH, Sorensen IA, Binder V: Familial occurrence of inflammatory bowel disease. N Engl J Med 1991; 324: 84-88.

6 Satsangi J, Parkes M, Jewell DP, Bell JI: Genetics of inflammatory bowel disease. Clin Sci (Colch) 1998; 94: 473-478.

7 Russel MG, Pastoor CJ, Janssen KM et al: Familial aggregation of inflammatory bowel disease: a population-based study in South Limburg, The Netherlands. The South Limburg IBD Study Group. Scand J Gastroenterol Suppl 1997; 223: 88-91.

8 Tysk C, Lindberg E, Jarnerot G, Floderus-Myrhed B: Ulcerative colitis and Crohn's disease in an unselected population of monozygotic and dizygotic twins. A study of heritability and the influence of smoking. Gut 1998; 29: 990-996.

9 Thompson NP, Driscoll R, Pounder RE, Wakefield AJ: Genetics versus environment in inflammatory bowel disease: results of a British twin study. BMJ 1996; 312: 95 - 96.

10 Hampe J, Schreiber S, Shaw SH et al: A genomewide analysis provides evidence for novel linkages in inflammatory bowel disease in a large European cohort. Am J Hum Genet 1999; 64: $808-816$.

11 Rioux JD, Silverberg MS, Daly MJ et al: Genomewide Search in Canadian Families with Inflammatory Bowel Disease Reveals Two Novel Susceptibility Loci. Am J Hum Genet 2000; 66: 1863 1870.

12 Cho JH, Nicolae DL, Gold LH et al: Identification of novel susceptibility loci for inflammatory bowel disease on chromosomes $1 \mathrm{p}, 3 \mathrm{q}$, and $4 \mathrm{q}$ : evidence for epistasis between $1 \mathrm{p}$ and IBD1. Proc Natl Acad Sci USA 1998; 95: 7502 - 7507.

13 Duerr RH, Barmada MM, Zhang L, Pfutzer R, Weeks DE: HighDensity Genome Scan in Crohn Disease Shows Confirmed Linkage to Chromosome 14q11-12. Am J Hum Genet 2000; 66: $1857-1862$.

14 Satsangi J, Parkes M, Louis E et al: Two stage genome-wide search in inflammatory bowel disease provides evidence for susceptibility loci on chromosomes 3, 7 and 12. Nat Genet 1996; 14: 199-202.

15 Ma Y, Ohmen JD, Li Z et al: A genome-wide search identifies potential new susceptibility loci for Crohn's disease. Inflamm Bowel Dis 1999; 5: 271-278.

16 Hugot JP, Laurent-Puig P, Gower-Rousseau C et al: Mapping of a susceptibility locus for Crohn's disease on chromosome 16. Nature 1996; 379: $821-823$.

17 Lander E, Kruglyak L: Genetic dissection of complex traits: guidelines for interpreting and reporting linkage results. Nat Genet 1995; 11: $241-247$.

18 Hampe J, Shaw SH, Saiz R et al: Linkage of inflammatory bowel disease to human chromosome 6p. Am J Hum Genet 1999; 65: $1647-1655$.
19 Duerr RH, Barmada MM, Zhang L et al: Linkage and association between inflammatory bowel disease and a locus on chromosome 12. Am J Hum Genet 1998; 63: 95 - 100.

20 Curran ME, Lau KF, Hampe J et al: Genetic analysis of inflammatory bowel disease in a large European cohort supports linkage to chromosomes 12 and 16. Gastroenterology 1998; 115: $1066-1071$.

21 Cavanaugh JA, Callen DF, Wilson SR et al: Analysis of Australian Crohn's disease pedigrees refines the localization for susceptibility to inflammatory bowel disease on chromosome 16. Ann Hum Genet 1998; 62: 291-298.

22 Ohmen JD, Yang HY, Yamamoto KK et al: Susceptibility locus for inflammatory bowel disease on chromosome 16 has a role in Crohn's disease, but not in ulcerative colitis. Hum Mol Genet 1996; 5: $1679-1683$.

23 Annese V, Latiano A, Bovio P et al: Genetic analysis in Italian families with inflammatory bowel disease supports linkage to the IBD1 locus - a GISC study. Eur J Hum Genet 1999; 7: 567 573.

24 Brant SR, Fu Y, Fields CT et al: American families with Crohn's disease have strong evidence for linkage to chromosome 16 but not chromosome 12. Gastroenterology 1998; 15: 1056-1061.

25 Lennard-Jones JE: Classification of inflammatory bowel disease. Scand J Gastroenterol Suppl 1989; 170: 2-6.

26 Boehnke M, Lange K, Cox DR: Statistical methods for multipoint radiation hybrid mapping. Am J Hum Genet 1991; 49: $1174-1188$.

27 Carey AH: Use of commercially available radiation hybrid panels; in Dracopoli NC, Haines JL, Krof BR et al. (eds): Current Protocols in Human Genetics. New York, 1997, vol 1, pp 3.5.13.5.10.

28 O'Connell JR, Weeks DE: PedCheck: a program for identification of genotype incompatibilities in linkage analysis. Am J Hum Genet 1998; 63: 259-266.

29 Lander ES, Green P: Construction of multilocus genetic linkage maps in humans. Proc Natl Acad Sci USA 1987; 84: 2363-2367.

30 Matise TC, Perlin M, Chakravarti A: Automated construction of genetic linkage maps using an expert system (MultiMap): a human genome linkage map. Nat Genet 1994; 6: 384-390.

31 Daly MJ, Kruglyak L, Pratt S et al: GENEHUNTER 2.0 - a complete linkage analysis system. Am J Hum Genet Suppl 1998; 63: A286.

32 Yang H, Plevy SE, Taylor K et al: Linkage of Crohn's disease to the major histocompatibility complex region is detected by multiple non-parametric analyses. Gut 1999; 44: 519-526.

33 Kruglyak L, Lander ES: Limits on fine mapping of complex traits [letter]. Am J Hum Genet 1996; 58: 1092-1093.

34 Becker KG, Simon RM, Bailey-Wilson JE et al: Clustering of nonmajor histocompatibility complex susceptibility candidate loci in human autoimmune diseases. Proc Natl Acad Sci USA 1998; 95: $9979-9984$

35 Bouma G, Xia B, Crusius JB et al: Distribution of four polymorphisms in the tumour necrosis factor (TNF) genes in patients with inflammatory bowel disease (IBD). Clin Exp Immunol 1996; 103: 391-396.

36 Bouma G, Oudkerk Pool M, Crusius JB et al: Evidence for genetic heterogeneity in inflammatory bowel disease (IBD); HLA genes in the predisposition to suffer from ulcerative colitis (UC) and Crohn's disease (CD). Clin Exp Immunol 1997; 109: 175 - 179.

37 Bouma G, Poen AC, Garcia-Gonzalez MA et al: HLA-DRB1*03, but not the TNFA-308 promoter gene polymorphism, confers protection against fistulising Crohn's disease. Immunogenetics 1998; 47: 451-455.

38 De La Concha EG, Fernandez-Arquero M, Santa-Cruz S et al: Positive and negative associations of distinct HLA-DR2 subtypes with ulcerative colitis (UC). Clin Exp Immunol 1997; 108: 392 395. 
39 Danze PM, Colombel JF, Jacquot S et al: Association of HLA class II genes with susceptibility to Crohn's disease. Gut 1996; 39: $69-72$.

40 Forcione DG, Sands B, Isselbacher KJ, Rustgi A, Podolsky DK, Pillai S: An increased risk of Crohn's disease in individuals who inherit the HLA class II DRB3*0301 allele. Proc Natl Acad Sci USA 1996; 93: 5094-5098.

41 Fernandez Arquero M, Lopez Nava G, De la Concha EG et al: HLA-DR2 gene and Spanish patients with ulcerative colitis. Rev Esp Enferm Dig 1998; 90: 243 - 249.

42 Heresbach D, Alizadeh M, Reumaux D et al: Are HLA-DR or TAP genes genetic markers of severity in ulcerative colitis? J Autoimmun 1996; 9: $777-784$.

43 Louis E, Satsangi J, Roussomoustakaki M et al: Cytokine gene polymorphisms in inflammatory bowel disease. Gut 1996; 39: $705-710$.

44 Negoro K, Kinouchi Y, Hiwatashi N et al: Crohn's disease is associated with novel polymorphisms in the $5^{\prime}$-flanking region of the tumor necrosis factor gene. Gastroenterology 1999; 117: $1062-1068$.

45 Plevy SE, Targan SR, Yang H, Fernandez D, Rotter JI, Toyoda H Tumor necrosis factor microsatellites define a Crohn's diseaseassociated haplotype on chromosome 6. Gastroenterology 1996; 110: $1053-1060$.

46 Reinshagen M, Loeliger C, Kuehnl P et al: HLA class II gene frequencies in Crohn's disease: a population based analysis in Germany. Gut 1996; 38: 538-542.
47 Satsangi J, Welsh KI, Bunce M et al: Contribution of genes of the major histocompatibility complex to susceptibility and disease phenotype in inflammatory bowel disease. Lancet 1996; 347: $1212-1217$

48 Trachtenberg EA, Yang H, Hayes E et al: HLA class II haplotype associations with inflammatory bowel disease in Jewish (Ashkenazi) and non-Jewish caucasian populations. Hum Immunol 2000; 61: 326-333.

49 Uyar FA, Imeryuz N, Saruhan-Direskeneli G et al: The distribution of HLA-DRB alleles in ulcerative colitis patients in Turkey. Eur J Immunogenet 1998; 25: 293 - 296.

50 Yoshitake S, Kimura A, Okada M, Yao T, Sasazuki T: HLA class II alleles in Japanese patients with inflammatory bowel disease. Tissue Antigens 1990; 53: $350-358$.

51 Su CG, Wen X, Bailey ST et al: A novel therapy for colitis utilizing PPAR-gamma ligands to inhibit the epithelial inflammatory response. J Clin Invest 1999; 104: 383 - 389.

52 Rioux JD, Daly MJ, Green T et al: Absence of linkage between inflammatory bowel disease and selected loci on chromosomes 3, 7, 12, and 16. Gastroenterology 1998; 115: $1062-1065$.

53 Vermeire S, Peeters M, Vlietinck R et al: Exclusion of linkage of Crohn's disease to previously reported regions on chromosomes 12,7 , and 3 in the Belgian population indicates genetic heterogeneity. Inflamm Bowel Dis 2000; 6: 165-170. 